\title{
Impact Factors Research for Carbon Emissions of Transportation Industry Based on Shapley Decomposition Method-an Analysis of Liaoning Province
}

\author{
Xiaoli Lu, Xiaofei Lv \\ Faculty of Management and Economics, \\ Dalian University of Technology, \\ Dalian, China
}

\begin{abstract}
By using the per-capita disposable income of urban residents, the freight turnover per ton of carbon emissions, the carbon emissions per ten thousands of passenger overturn and the ratio of output value of secondary and tertiary industry, this paper proposes a model of the carbon emissions by the transportation industry of Liaoning province. This paper utilizes the Shapley decomposition method, and then analyzes the influences of them on the carbon emissions by the transportation industry of Liaoning province in terms of the data of Liaoning province between 1997 and 2010. The conclusions are: the carbon emissions per ten thousands of passenger overturn has the most influence on carbon emissions by the transportation industry, and the ratio of output value of secondary and tertiary industry has the least. Therefore, this paper supposes that the ideologies like purchasing energyefficient transport and using public transportation should be popularized, and improving the utilization of transport is also a crucial measure to reduce the carbon emissions by the transportation industry.
\end{abstract}

Keywords-transportation industry; carbon emissions; impact factors; Shapley decomposition method

\section{INTRODUCTION}

With the continuous development of global transportation, energy consumption is growing. In 2009, the International Energy Agency released the report, the global carbon emissions increased by $13 \%$ over the past 10 years, the transportation industry accounted for $25 \%$ [1]. Therefore, the transportation has become the major source of carbon emissions per unit area in the second largest industry after commerce [2]. Analyze the industry of carbon emissions of transportation has very important practical significance to reduce the total amount of the national carbon emissions and achieve a low carbon economy.

Domestic scholars have tried to use different methods to study transport carbon emissions influence factors. Yanan Xu use STIRPAT model to analyze the factors of China transportation carbon emissions, results show that the influence on the carbon emissions of different age groups is different [3]; Jian-hui zhang etc., according to urban low-carbon transport system dynamics model, describe the complex interaction relationship between various factors [4]; Kai-ya wu decompose analysis of shanghai transportation fields such as the change of energy consumption carbon emission by using LMDI decomposition technique, the research shows that the energy structure play an important role in reduce carbon emissions, but with weak to lower carbon intensity [5].

At present, the commonly carbon factor decomposition method is Laspeyres decomposition and LMDI decomposition method. Among them, the Laspeyres decomposition method was widely used because of its simple operation, but the residuals problems of calculation process make the application of the method restricted. While the LMDI decomposition method has the advantages of unique and intelligibility but not be able to process with zero value and negative value data of defects. Compared with the previous research methods, Sharp decomposition method as a regression equation to measure variables on the dependent variable contribution, is suitable for almost all determining equation, quantitative observation in the regression variables on the dependent variable contribution of the difference and dealing with the endogeneity of the variables and the random error and other advantages. Therefore, Shapley decomposition method is introduced in the transport of carbon emissions in the study, on the basis of predecessors' research results to analyze the influence factors of transport carbon emissions.

\section{THE MEASURE METHODS AND EQUATIONS}

\section{A. Shapley decomposition method}

The basic idea of Shapley decomposition method is assuming that the influencing factors of transport carbon emissions collection $\mathrm{G}$ contain $\mathrm{n}$ elements, each factor in $f_{i}, i=1,2, \cdots, n$. And one of the s factor to form a new set
$N=\left\{x_{1}, x_{2}, \cdots, x_{i}, \cdots, x_{s}\right\}$,$\quad \mathrm{N}$ is a non empty set of $\mathrm{G}$. Therefore, set $\mathrm{N}$ have s-1 factor that come from the $\mathrm{n}-1$ factor of set $G$, influence factors of new set $\mathrm{N}$ in combination number is shown in formula (1)

$$
\frac{(n-1) !}{(s-1) ![(n-1)-(s-1)] !}
$$

Set $N$ characteristic function is $\{N\}$, if after eliminating factors from $\mathrm{N}$ the characteristic function of $\mathrm{w}\{\mathrm{N}-1\}$, then the contribution of factor $\mathrm{x}_{\mathrm{i}}$ to set $\mathrm{N}$ is shown in formula (2):

$$
\omega\{N\}-\omega\{N-i\}
$$


According to the contribution of the Sharp decomposition method shows the influence factors on carbon emissions size. If the contribution is positive, the influence factors on the transport carbon emissions have promoting effect, the larger the value, the bigger the effect. Conversely, if the factors have inhibition to transport carbon emissions, the greater the absolute value of value, the stronger the inhibition. At the same time, Sharp value can reflect the influence factors in the degree of important factors, that is the greater the sharp value, the bigger the influence. If the different factors in the Sharp values, it represents the greater relevance.

Set a Shapley value is $S\left(f_{i}\right)$, and then the formula can be defined as when from $\mathrm{s}$ from 1 to $\mathrm{n}$ the formula is (3)

$$
S\left(f_{i}\right)=\sum_{1}^{n} \frac{(s-1) !(n-s) !}{n !}[w\{N\}-w\{N-1\}]
$$

\section{B. Carbon emissions measurement equation}

Identify the factors influencing transport carbon emissions is the foundation of carbon emission measure model. Jiancui Liu think the transportation sector carbon emissions is the result of many factors combined with a regional city level, economic development level and the income level, but the degree of influence of various factors on carbon emissions is different [6]. Based on the above study results, this paper identifies factors of carbon emissions in the transport sector from the population quantity, the residents living conditions and economic development dimensions. According to representative and high frequency principle, this paper will use the per capita disposable income of urban residents $\left(V_{Y}\right)$, the output value of the secondary and tertiary industries $\left(R_{E V A}\right)$, the realization of carbon emissions per ton $(A)$, and carbon emission caused by passenger turnover per ten thousand people ( $B$ ), four indicators to measure the traffic transportation industry of carbon emissions. Each tone of carbon emission to achieve the quantity of every ten thousand people $(A)$ and passenger turnover caused by carbon emissions ( $B$ ) expressions is as follows:

$$
A=\frac{P R_{\operatorname{Tran}}}{C} B=\frac{C}{P E_{\text {Tran }}}
$$

On the type, $\mathrm{C}$ is transport carbon emissions, $P R_{\text {Tran }}$ is the freight turnover and $P E_{\text {Tran }}$ is passenger turnover.

This paper adopts double logarithm linear model to log data processing, as shown in formula (5) is constructed of carbon emissions measurement equation:

$$
\begin{aligned}
& L n C=\beta_{0}+\beta_{1} L n V_{\mathrm{Y}}+\beta_{2} L n \frac{P R_{\text {Tran }}}{C}+ \\
& \beta_{3} L n \frac{C}{P E_{\text {Tran }}}+\beta_{4} R_{E V A}+u+d
\end{aligned}
$$

In the equation, $\beta_{1}, \beta_{2}$, and $\beta_{3}$, respectively represent the per-capita disposable income of urban residents, the freight turnover per ton of carbon emissions, the carbon emissions per ten thousands of passenger overturn change $1 \%$, the transport carbon emissions relative amount of change $\beta_{1} \%, \beta_{2} \%$, and $\beta_{3} \%$. $\beta_{4}$ said when the secondary and tertiary industry output value more than change 1 unit, transportation industry is $\beta_{4} \%$ the relative change of the carbon emissions. $\beta_{0}$ as constant; $u$ to intercept together; $d$ for the virtual variables.

\section{DATA SOURCES AND PROCESSING}

This article selects the data mainly comes from the Liaoning province statistical yearbook from 1998 to 2011. Because of not explicitly labeled yearbook of transport carbon emissions, according to the IPCC emissions calculation guidelines for Liaoning province transport carbon emissions, its formula as shown in formula (6):

$$
C=\sum_{i=1}^{n} E_{i} \times F_{i} \times K_{i}
$$

Among them, the $C$ is transport carbon emissions (t); $n$ is energy types; $i$ is the first $i$ kind of energy; $E_{i}$ is the kind of energy consumption according to the standard coal meter; $F_{\mathrm{i}}$ and $K_{\mathrm{i}}$, respectively the first kind of energy conversion coefficient of energy. Which refer to the national development and reform commission recommended value of standard coal carbon emissions coefficient 2.4567 (t/tce), which is 1 tons of standard coal from 2.4567 tons of carbon dioxide emissions.

This article uses the statistical analysis software SPSS17.0. The log data processing is shown in Table I. Using the least squares estimate method to minimize error square to achieve.

\section{THE EMPIRICAL RESEARCH}

\section{A. The establishment of carbon emissions measurement equation}

This paper first have a regression analysis. Through this the adjusted $\mathrm{R}$ square value is 0.973 , the estimated standard error is 0.064 . Therefore, the fitting degree is good for the transport carbon emissions measurement equation, and is good for the carbon explanation. In addition, according to the results of the regression analysis of various factors (Table II), four indicators were selected in this paper through the $T$ test, the whole carbon decision equation under $10 \%$ significance level through the test. In the four factors in addition to the carbon emissions per ton of cargo turnover, the other three factors are positive, The results show that the carbon emissions per ton increase in turnover can inhibit the increase of transport carbon emissions, while the other three factors of the increase will promote the growth of carbon emissions. In view of the influence degree of the independent variable on the dependent variable, town residential disposable income and ten thousand carbon emissions per passenger turnover increased by $1 \%$, the transport carbon emissions will increase $0.513 \%$ and $0.467 \%$, respectively, the carbon emissions per ton of freight turnover increase by $1 \%$, the transport carbon emissions will fall by $0.466 \%$. 
each Secondary and tertiary industry output value increase an additional unit, the transport carbon emissions will increase by $0.334 \%$. Through the above analysis, this paper establishes the transportation industry in Liaoning province carbon emissions measurement equation, as shown in equation of (7)

TABLE I. THE LOGARITHMIC TREATMENT OF ORIGINAL DATA.

\begin{tabular}{|c|c|c|c|c|c|}
\hline Years & $\begin{array}{l}\text { Carbon Emissions of } \\
\text { Transportation } \\
\text { Industry }\end{array}$ & $\begin{array}{c}\text { Per-Capita } \\
\text { Disposable Income } \\
\text { of Urban Residents }\end{array}$ & $\begin{array}{c}\text { The Freight } \\
\text { Turnover Per Ton } \\
\text { of Carbon } \\
\text { Emissions }\end{array}$ & $\begin{array}{c}\text { The Carbon } \\
\text { Emissions per Ten } \\
\text { Thousands of } \\
\text { Passenger Overturn }\end{array}$ & $\begin{array}{l}\text { The Ratio of } \\
\text { Output Value of } \\
\text { Secondary and } \\
\text { Tertiary Industry }\end{array}$ \\
\hline 1997 & 6.63 & 8.42 & 17.53 & 9.71 & 1.28 \\
\hline 1998 & 6.70 & 8.44 & 17.76 & 9.74 & 1.24 \\
\hline 1999 & 6.76 & 8.50 & 17.69 & 9.76 & 1.21 \\
\hline 2000 & 7.06 & 8.59 & 17.98 & 9.99 & 1.29 \\
\hline 2001 & 7.43 & 8.67 & 18.32 & 10.31 & 1.19 \\
\hline 2002 & 7.42 & 8.78 & 18.29 & 10.26 & 1.16 \\
\hline 2003 & 7.37 & 8.89 & 18.00 & 10.28 & 1.17 \\
\hline 2004 & 7.45 & 8.99 & 17.87 & 10.17 & 1.09 \\
\hline 2005 & 7.98 & 9.12 & 18.27 & 10.68 & 1.17 \\
\hline 2006 & 8.07 & 9.25 & 18.17 & 10.66 & 1.20 \\
\hline 2007 & 8.19 & 9.42 & 17.94 & 10.71 & 1.24 \\
\hline 2008 & 8.19 & 9.57 & 17.75 & 10.61 & 1.38 \\
\hline 2009 & 8.25 & 9.67 & 17.71 & 10.61 & 1.34 \\
\hline 2010 & 8.30 & 9.78 & 17.61 & 10.59 & 1.46 \\
\hline
\end{tabular}

TABLE II. REgRESSION ANALYSIS RESULTS.

\begin{tabular}{|c|c|c|c|c|}
\hline \multirow{2}{*}{ Model } & \multicolumn{2}{|c|}{ Unstandardized Coefficients } & \multirow{2}{*}{$t$} & \multirow{2}{*}{ Sig. } \\
\hline & $\mathrm{B}$ & Std. Error & & \\
\hline Constant & 3.864 & 0.905 & 1.439 & 0.097 \\
\hline Per-capita disposable income of urban residents & 0.513 & 0.060 & 8.482 & 0.000 \\
\hline The freight turnover per ton of carbon emissions & -0.466 & 0.185 & -2.517 & 0.033 \\
\hline $\begin{array}{l}\begin{array}{c}\text { The carbon emissions per ten thousands of } \\
\text { passenger overturn }\end{array} \\
\end{array}$ & 0.467 & 0.221 & 2.119 & 0.063 \\
\hline $\begin{array}{l}\text { The ratio of output value of secondary and tertiary } \\
\text { industry }\end{array}$ & 0.334 & 0.171 & 1.923 & 0.075 \\
\hline
\end{tabular}

TABLE III. CALCULATION DECOMPOSITION RESUlts.

\begin{tabular}{|c|c|c|c|c|}
\hline \multirow[b]{2}{*}{ Year } & \multicolumn{4}{|l|}{ Contribution (\%) } \\
\hline & $\begin{array}{l}\text { Per-capita Disposable } \\
\text { Income of Urban Residents }\end{array}$ & $\begin{array}{l}\text { The Freight Turnover Per } \\
\text { Ton of Carbon Emissions }\end{array}$ & $\begin{array}{l}\text { The Carbon Emissions Per } \\
\text { Ten Thousands of } \\
\text { Passenger Overturn }\end{array}$ & $\begin{array}{l}\text { The Ratio of Output Value } \\
\text { of Secondary And Tertiary } \\
\text { Industry }\end{array}$ \\
\hline 1997 & -30.08 & 18.21 & -27.15 & 1.17 \\
\hline 1998 & -29.06 & 7.49 & -25.75 & -0.09 \\
\hline 1999 & -25.98 & 10.75 & -24.82 & -0.99 \\
\hline 2000 & -21.36 & -2.76 & -14.08 & 1.44 \\
\hline 2001 & -17.26 & -18.61 & 0.87 & -1.73 \\
\hline 2002 & -11.62 & -17.21 & -1.47 & -2.95 \\
\hline 2003 & -5.97 & -3.69 & -0.53 & -2.62 \\
\hline 2004 & -0.84 & 2.36 & -5.67 & -5.17 \\
\hline 2005 & 5.83 & -16.28 & 18.15 & -2.31 \\
\hline 2006 & 12.50 & -11.62 & 17.21 & -1.37 \\
\hline
\end{tabular}




\begin{tabular}{|l|l|l|l|l|}
\hline 2007 & 21.22 & -0.90 & 19.55 & -0.24 \\
\hline 2008 & 28.91 & 7.96 & 14.88 & 4.39 \\
\hline 2009 & 34.04 & 9.82 & 14.88 & 3.31 \\
\hline 2010 & 39.68 & 14.48 & 13.94 & 7.15 \\
\hline Shapely value & 1.1180 & 1.4375 & 2.1169 & 0.1266 \\
\hline
\end{tabular}

$L n C=3.864+0.513 \operatorname{Ln} V_{Y}+(-0.466) \operatorname{Ln} \frac{P R_{\text {Tran }}}{C}+0.467 L n \frac{C}{P E_{\text {Tran }}}+0.334 R+d$

\section{B. Results analysis}

In this paper, using the formula, decomposition for the transportation industry in Liaoning province carbon emissions is calculated, the result as shown in Table III.

Disposable income of urban residents during 1997 to 2004, the contribution value is always negative, and presents growth trend. After 2005, the disposable income of urban residents of the contribution is positive (5.83). The reasons for this phenomenon is that as the income of urban residents continue to improve, the way of life is changed, such as residents increased to civilian automobile quantity demand growth times, go out travel. These factors have increased the demand for transportation and frequency of use, resulting in transportation industry, the growth of carbon emissions. Therefore, the government should take such as increasing the low emission vehicles promotion, increase low emission vehicles subsidies, increase the relationship on the big car tax and other measures to balance the needs of the residents and energy saving and emission reduction.

The freight turnover per ton of carbon emissions to achieve the degree of contribution from 1997 to 2010 period shows alternating obvious. Among them, the values are always negative between 2000 and 2007, and then keep at the levels of more than $7.96 \%$ in 2008 . So under the condition of time and space distance between regions greatly shorten, the major areas of Liaoning province highway freight turnover speed and improved to reduce the freight turnover of total carbon emissions produced by Ref. [7].

Per ten thousand passenger turnover of carbon variables in 1997 and 2004 have been negative. But since 2005, the contribution of each million passenger carbon variables are always between $10 \%$ and $20 \%$, the transportation is always positive contribution. The main reasons for this phenomenon is in recent years along with the Liaoning province civilian cars and rising travel frequency, fuel consumption and carbon dioxide emissions also increased, which resulted in the shunt public traffic tourist increasing phenomenon, so every million people transport turnover of carbon emissions variable contributions in 2005 after the beginning in 10\% above, and leads to an increase in Liaoning province transportation sector carbon emissions.

Secondary and tertiary industry output value of the ratio of contribution during the period of 1998-2007 is always negative. After 2008, the contribution of positive degree always below $10 \%$. This shows that in the period from 2008 to 2010 secondary and tertiary industry output value ratio decreased inhibition contributes to the transportation industry the growth of carbon emissions and the inhibition enhanced year by year. At the same time, according to the development experience of developed countries, the optimization of the industrial structure will indeed reduce transport emissions [8-9]. although the industrial structure of Liaoning province has the obvious adjustment in recent years, and in 2008 after the secondary and tertiary industry output value has positive effects on reducing carbon emissions in Liaoning province transportation industry, but the distance from the developed countries still there is a large gap between, this shows that Liaoning province transportation industry still has great potential of emission reduction. Therefore, the future through the development of the third industry, reasonable and gradually reduced second industries in the economy in the proportion of not only is an effective way to long-term energy-saving emission reduction, speed up the adjustment of economic structure and the transportation.

\section{CONCLUSION}

The application of Shapely decomposition method has conducted the research to the carbon emissions of transportation industry in Liaoning province from 1997 to 2010. The results show that, in the four factors (per capita disposable income of urban residents, freight turnover per ton of carbon emissions, the carbon emissions per ten thousands of passenger overturn and the secondary and tertiary industry output value), the contribution of the carbon emissions per ten thousands of passenger overturn is the largest, and the secondary and tertiary industry output value is the minimum. The results such as ever to do with su tao, jian-hui zhang, cyl ma jin [10] and many scholars such as Ma Wei [11] close results, it shows that this article adopted four explanatory variables have a certain scientific and practical explanation ability.

Under the current situation of urbanization and modernization in China control the number of civilian vehicles as well as the promotion of new energy, low emission of private cars and a series of leading policy will be important and positive impact on transport carbon emissions. To optimize traffic structure, improve the transport network layout and encourage citizens to use public transportation and other measures can effectively improve the utilization and transportation efficiency, so as to reduce transport energy consumption per unit of purpose. It will have a long-term impact with the economic restructuring and development of the tertiary industry to reduce the transport carbon emissions. 


\section{ACKNOWLEDGMENTS}

The research work was supported by National Natural Science Foundation of major international cooperation projects under Grant No. 71320107006 and National Natural Science Foundation of china under Grant No. 41201174.

\section{REFERENCES}

[1] Guomin Li, Ke Lu, Reform and path of urban land low-carbon use patterns [J]. China Population Resources and Environment, 20(12), pp. 6-65, 2010.

[2] Rong xin Zhao, Xian jin Huang, Taiyang Zhong, China's carbon intensity of different industrial spatial and carbon footprint analysis [J]. Journal of Geographical, 65(9), pp. 1048-1057, 2010.

[3] Jianhui Zhang, Zhiping Du, Carbon measure of transportation industry in China and the factorization [J]. Logistics Technology, 30(6), pp. 16-19, 2011.

[4] Zhongjie Li, Yixin Zheng, Yunbo Chen, et al., Kunming transport carbon emissions characteristics and problem resolution [J]. China Population Resources and Environment, 21(3), pp. 5053-5508, 2011.
[5] Kaiya Wu, Caihong He, Guixin Wang, Hao Zhang, Shanghai transport energy consumption carbon emissions measurement and decomposition analysis [J]. Economic Geography, 32(11), pp. 4551, 2012.

[6] Jiancui Zhang, China's transportation and energy saving potential and carbon emissions prediction [J]. Journal of Resources Science, (4), pp. 641-645, 2011.

[7] Chun-xia wang, On the basis of urban agglomeration highway network layout optimization research [D]. Northeastern University, Shenyang, 2009.

[8] Yong-bin zhu, Liu Changxin Wang Zheng ya-juan shi, The trend of the industrial structure evolution and its potential to reduce emissions analysis [J]. Chinese Soft Science, (2), pp. 35-42, 2013.

[9] Yue-ping wang, Quantitative analysis of the impact of transportation development of industrial structure [J]. Management of the World, (6), pp. 65-72, 2004.

[10] Cyl ma jin, yan-wei chai, Liu Zhilin, Based on the travel behavior of residents of Beijing traffic emissions impact mechanism [J]. Journal of Geographical, 66(8), pp. 1023-1032, 2011.

[11] Ma Wei, ya-hua wang, Liu Shenglong, Transport infrastructure and China's population migration: based on analysis of gravity model [J]. Chinese Soft Science, (3), pp. 69-76, 2012. 